\title{
Cyanobacterial Natural Products for the Inhibition of Biofilm Formation and Biofouling
}

\author{
Karl Gademann*
}

\begin{abstract}
Biofouling is defined by the non-specific attachment of biological material (proteins, carbohydrates, prokaryotic cells and higher organisms) to surfaces upon their exposure to any biological fluid. Biofouling is a serious problem in many areas ranging from marine technology, nuclear power plants, dentistry, food processing to biomedical implants. This process can be addressed either actively by chemical compounds inhibiting growth, settlement or biofilm formation, or passively by generating repellent or resistant surfaces. This highlight article gives an overview over different secondary metabolites from cyanobacteria useful in this context. A candidate for active antifouling is nostocarboline, a carboline alkaloid from Nostoc. It has distinct and powerful activities against both prokaryotic and eukaryotic photosynthetic organisms. This compound is a candidate for the replacement of toxic tributyltin (TBT) antifouling coatings. Another passive strategy is presented utilizing the strong binding of anachelin to metal oxide surfaces. This anchor binds polyethyleneglycol (PEG) efficiently to surfaces and renders $\mathrm{TiO}_{2}$ protein resistant. This anchor displays superior properties when compared to dopamine or DOPA, a key constituent in mussel adhesive proteins (MAP). Implications for biomaterials design are discussed.
\end{abstract}

Keywords: Advanced materials $\cdot$ Chemical biology $\cdot$ Cyanobacteria $\cdot$ Natural products $\cdot$ Synthesis

\section{Introduction}

The evolutionary wisdom enshrined in natural products provides the rationale for their massive success related to important problems of our society.[1] Major advances in key areas such as health and nutrition over the last century were made possible by understanding and exploiting the properties of biogenic compounds. ${ }^{[2]}$ In particular, a significant part of the increase both in life expectancy and quality of life was made possible through the understanding and administration of vitamins, the identification of natural toxins and also the discovery of natural-product derived drugs. ${ }^{[1,2]}$ Natural substances always played a key role in drug discovery, ${ }^{[3]}$ recent surveys attribute up to

\footnotetext{
${ }^{*}$ Correspondence: Prof. Dr. K. Gademann Ecole Polytechnique Fédérale de Lausanne (EPFL) Chemical Synthesis Laboratory EPFL-SB-ISIC-LSYNC

$\mathrm{CH}-1015$ Lausanne

E-Mail: karl.gademann@epfl.ch
}

$40 \%$ of new chemical entities introduced on the market between 1981 and 2002 to natural products or derivatives. ${ }^{[4]}$ This warrants both the search for new natural products and the identification of key molecular processes in nature.

Biofouling can be defined as the unspecific adsorption of biological material onto surfaces upon their immersion in a biological fluid. ${ }^{[5,6]}$ Every object in contact with any biological fluid is exposed to biofouling. This process thus presents a significant challenge in various areas ranging from marine infrastructure (ships, pipelines, oil platforms), dentistry, nuclear power plants, food processing, to human medical body implants. Biofouling occurs in several stages: In the initial steps, molecules (from small organic compounds to large proteins and oligosaccharides) are attached to the surface (molecular fouling). Gradually, cellular organisms attach to this layer, such as bacteria and algae in aquatic environments and, in later stages of marine biofouling, higher organisms such as barnacles, insect larvae and mussels. In the microfouling of implants, macrophages and later fibroblasts play an important role. In addition, colonization by harmful bacteria is a frequent cause of nosocomial infections, which are considered a leading cause of pathogenrelated deaths in hospitals. In later stages of implant-related biofouling, encapsulation by tissue terminates the process, which, in connection with bacterial infections, adds further problems to the therapy of nosocomial infections. The economic impact of biofouling is very high, for example, marine biofouling directly contributes to increased fuel costs, higher maintenance, increased corrosion and decreased lifetime of marine infrastructure. In addition, the current strategy against marine biofouling is using toxic tributyltin (TBT) coatings, which are increasingly banned worldwide. ${ }^{[7]}$ Increasing resistance of aquatic species to $\mathrm{Cu}$ further contributes to the need of novel antifouling agents. In implant-related biofouling, nosocomial infections are very difficult to treat because of the encapsulation of tissue and, moreover, implant rejection or stent overgrowth, which impairs the desired implant function. The economic and social burden thus placed on patients and their families is very high. For all these reasons, it becomes clear that the challenge of biofouling must be successfully addressed using chemical strategies in areas ranging from marine infrastructure to biomedical devices. Molecular solutions to biofouling are provided by two fundamental strategies, i.e. active and passive inhibition. Active treatments of biofouling are generally characterized by molecules inhibiting the biofouling 


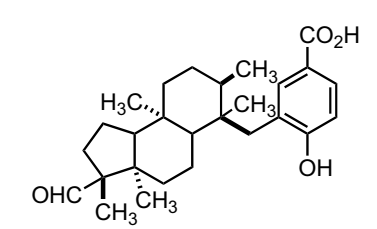

Comnostin B

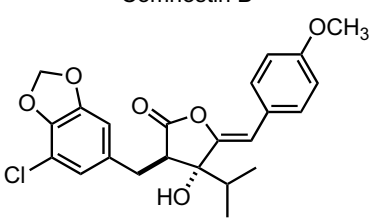

Cyanobacterin
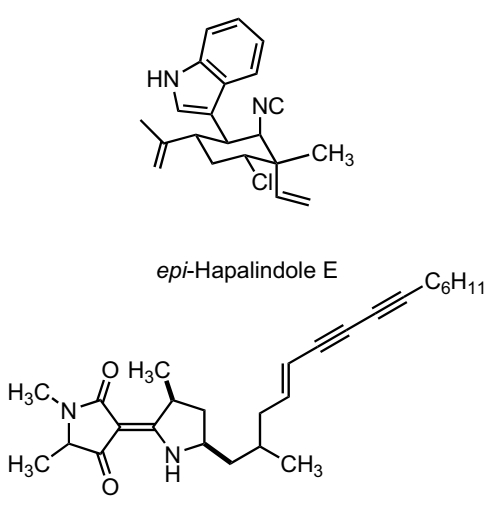

Fischerellin A
Fig. 1. Representative cyanobacterial metabolites displaying molluscicidal (comnostin B), antibacterial and antifungal (epi-hapalindole E), and antialgal (cyanobacterin, fischerellin $A$ ) activities process. Passive solutions to biofouling include surface modifications that inhibit the process of biofilm formation. Several excellent reviews have been published on natural products and biofouling. ${ }^{[8-16]}$ In this highlight article, we will review our own research efforts regarding both active and passive inhibition of biofouling with relevance both to marine environments and biomedical devices.

\section{Active Inhibition of Biofouling}

Cyanobacteria (so-called blue-green algae) are prokaryotic autotrophs that perform photosynthesis. These organisms populate many diverse mostly humid or aquatic habitats ranging from small ponds to the open ocean. Both planktonic and benthic species are known, and the latter have been very successful in forming persistent biofilms in aquatic environments. For these benthic cyanobacteria, a significant challenge resides in aquatic organisms competing for the same resources such as space and light. In particular, overgrowth by competing algae is a central threat to benthic biofilm-forming cyanobacteria. One defense strategy against such competition consists of the production and secretion of deterrence chemicals that slow down or stop biofilm formation by competing life forms. Cyanobacteria, prolific producers of secondary metabolites with large chemical diversity, have thus been regarded for some time as a prime source of antifouling compounds that inhibit biofouling through active mechanisms. ${ }^{[14,16]}$ The large structural variety of the compounds as well as their potent bioactivity has sparked large interest in their isolation and characterization. Many bioactivities can be useful in preventing biofouling, for example, in the initial stages, antibacterial, antifungal and antialgal activities are desired.
Some representative cyanobacterial metabolites displaying such properties are shown in Fig. 1. The diterpenoid comnostin $\mathrm{B}$, isolated from Nostoc commune, displays a strong molluscicidal effect against Biomphalaria glabrata. ${ }^{[17]}$ Epi-hapalindole E, [18] epimeric to hapalindole $E^{[19]}$ at the quaternary center, displayed a wide range of cytotoxcities, with antibacterial, antifungal, antialgal and activities against mammalian cells reported.[20] Cyanobacterin, isolated from Scytonema hofmanni, is a potent algicide against a large variety of photosynthetic organisms. ${ }^{[21,22]}$ Fischerellin, isolated from Fischerella musicola, is a very potent algicide (minimum inhibitory concentration [MIC]) $14 \mathrm{nM}$ against Synechococcus, and also displays antifungal activities. ${ }^{[23-25]}$

There are only few indole alkaloids known from cyanobacteria (Fig. 2). In addition to the hapalindoles, biosynthetically related welwitindolines featuring very welwitindoline A isonitrile features a spiro-bicyclo[4.2.0]octene-oxindole moiety. ${ }^{[26]}$ Another class of important indole derived metabolites are the tjipanazoles, isolated from Tolypothrix tjipanasensis. ${ }^{[27]}$ These compounds share the same indolo[2,3-a]carbazole core as antitumor compounds such as rebeccamycin, ${ }^{[28,29]}$ staurosporine ${ }^{[30-32]}$ or the synthetic enzastaurin (LY317615, antidiabetes activity). [33,34] The indolo[2,3-a]carbazole scaffold of the tjipanazoles is chlorinated to varying degrees and is glycosylated by different sugars. The biological activity of these compounds is characterized by interesting antifungal properties. In the context of a screening program against Plasmodium, two new indoloquinonones, calothrixin $\mathrm{A}$ and $\mathrm{B}$, were isolated from Calothrix in 1999. [35] These compounds contain an indolo[3,2-j]phenanthridine skeleton, which is unprecedented in other natural products, and they display antiplasmodial and cytotoxic behavior.

Only three carboline alkaloids have been isolated so far from cyanobacteria, Moore and coworkers described the antiviral Bauerines A-C from Dichotrix (Fig. 3). ${ }^{[36]}$ Norharmane, which like harmane is frequently found in higher plants, was isolated from the blue-green alga Nodularia harveyana by Volk. ${ }^{[37]}$ This compound was later shown in a thin layer chromatography assay to have a 'minimum toxic quantity' ranging from 1-4 $\mu \mathrm{g}$ against Arthrospira laxissima, Chroococcus minutus, Nostoc carneum, Nostoc insulare, Synechocystis aquatilis and Synechococcus sp. ${ }^{[38]}$ These values complemented earlier studies by Kodani et al., which showed inhibition at $30 \mu \mathrm{g} /$ disk against a panel of algae. ${ }^{[39]}$ In appealing structures were isolated from Hapalosiphon welwitschii. For example,

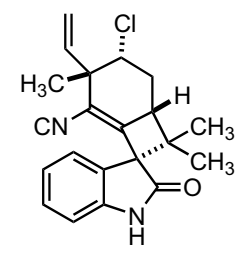

Welwitindoline A isonitrile<smiles>O=C1c2c[n+]([O-])c3ccccc3c2C(=O)c2c1[nH]c1ccccc21</smiles>

Calothrixin A<smiles></smiles>

Tjipanazole A

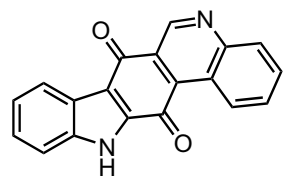

Calothrixin B<smiles>O=C1NC(O)C2=C1c1cc(Cl)ccc1Nc1[nH]c3ccc(Cl)cc3c12</smiles>

Tjipanazole J

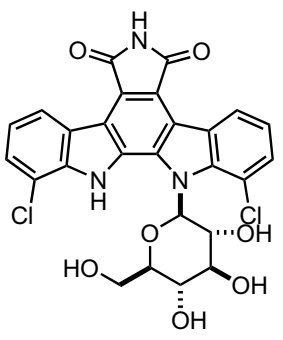

Rebeccamycin
Fig. 2. Cyanobacterial metabolites containing an indole fragment 


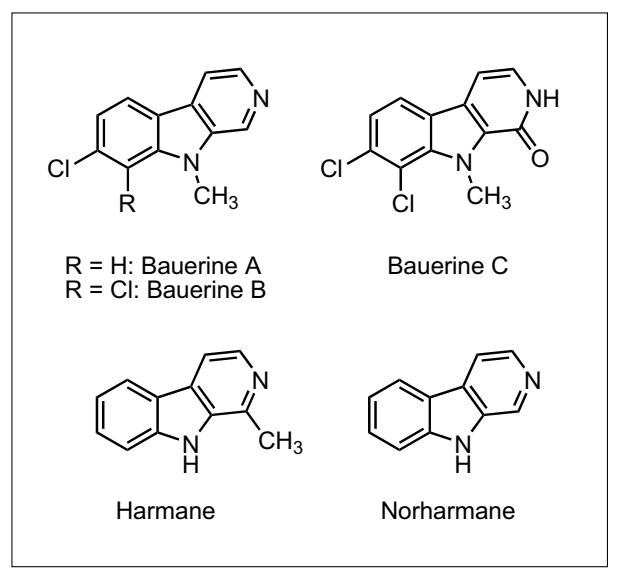

Fig. 3. Carboline alkaloids from cyanobacteria

subsequent studies, Volk and Furkert used microwell plate assays to better characterize MIC values and found MIC values $>100$ $\mu \mathrm{M}$ against a panel of five cyanobacteria after two days of incubation. ${ }^{[40]}$ Prolonged exposure gave better MIC values such as $39 \mu \mathrm{M}$ against Nostoc insulare. Most recently, cytotoxic properties of this metabolite were investigated but found to be rather low. ${ }^{[41]}$

We have recently reported the isolation and structural characterization of the carbolinium alkaloid nostocarboline from the cyanobacterium Nostoc 78-12A. ${ }^{[42]}$ This cyanobacterial strain was originally isolated by Flores and Wolk from a waste water lagoon and reported as bioactive. ${ }^{43]}$ Bioassay guided fractionation and screening for cholinesterase properties led to the isolation of nostocarboline (Fig. 4). ${ }^{[42]}$ This alkaloid, featuring a $\mathrm{Cl}$ substituent in the 6-position, is a potent inhibitor of butyrylcholinesterase with an $\mathrm{IC}_{50}$ of $13.2 \mu \mathrm{M}$. Interestingly, the corresponding compound lacking the $\mathrm{Cl}$ substituent, 2-methyl-norharmanium, was isolated from post mortem human brain, ${ }^{[44]}$ but is regarded as an 'orphan ligand' with an unknown receptor. We have measured also a strong inhibition of butyrylcholinesterase by this compound $\left(\mathrm{IC}_{50}=11.2 \mu \mathrm{M}\right)$ thus suggesting a potential biological role for this orphan ligand. ${ }^{[42]}$

The producer strain, Nostoc 78-12A was reported as anticyanobiotic by Flores and Wolk, ${ }^{[43]}$ so we next investigated whether nostocarboline was the responsible compound for this activity. Indeed, nostocarboline was shown to inhibit the growth of the toxic cyanobacterium Microcystis aeruginosa, the non-toxic cyanobacterium Synechococcus and the eukaryotic greenalga Kirchneriella contorta at $1 \mu \mathrm{M}$ concentration. ${ }^{[45]}$ A typical growth curve for Microcystis is shown in Fig. 5, where fast reduction of cyanobacterial cell population was measured after addition. The minimum planktocidal concentration, i.e. at which rapid death was observed, can be estimated between $1-10 \mu \mathrm{M}$ as evident from Fig. 5. ${ }^{[45]}$ The producer, which is also a photosynthet-

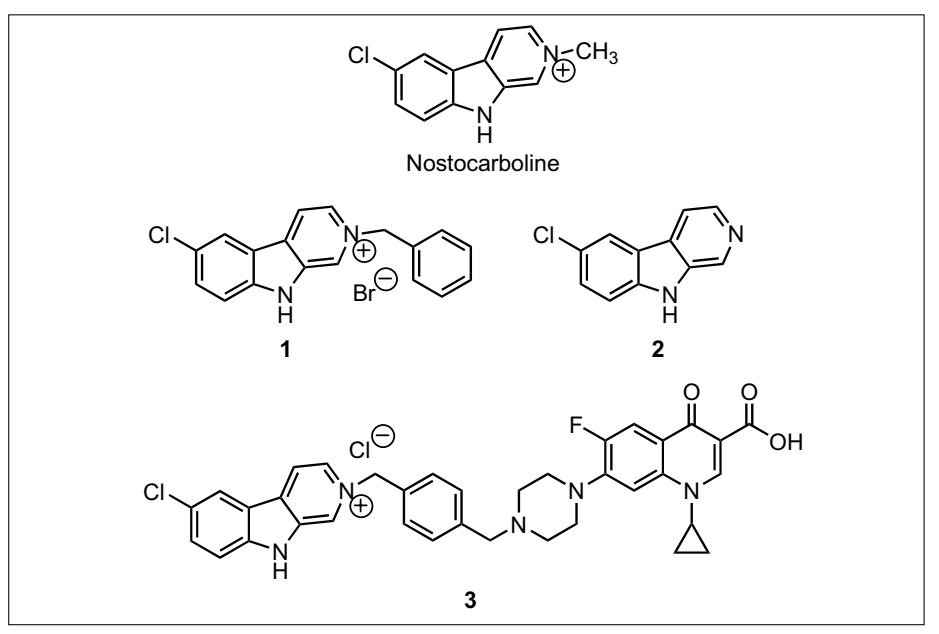

Fig. 4. Nostocarboline and derivatives ic organism, is affected by nostocarboline at much higher concentrations, and this difference in toxicity by at least a factor of 50 is probably responsible for the ecological advantage by the secretion of this compound.

We have performed quantitative structure-activity relationships (SAR) on nostocarboline ${ }^{[45]}$ by preparing several derivatives. We have found that aromatic $\mathrm{N}$-substitution by benzyl groups leads to increased activity (e.g. 1 in Fig. 4), where MIC values such as $100 \mathrm{nM}$ were observed. This very low value is remarkable in cellbased in vivo assays, as the charged active compound has to enter the cell and find its target at this low concentration. Variation of the chlorination pattern is tolerated without much loss of activity. Essential for biological activity was however quaternization, as the corresponding derivatives lacking $\mathrm{N}$-substituents (e.g. 2) were found to be inactive below $100 \mu \mathrm{M}$. This is interesting, as harmane and norharmane have been reported to have anticyanobacterial activities, although the reported values were measured either in different assays, or significantly higher than the ones found for the quaternized nostocarboline. We have thus demonstrated that $\mathrm{N}$-methylation leads to an increase in activity at least by two to three orders of magnitude. ${ }^{[45]}$ We have also prepared natural product hybrids ${ }^{[46-48]}$ such as $\mathbf{3}$, by hybridizing nostocarboline to the well-known antibacterial agent ciprofloxacin. ${ }^{[45]}$ This hybrid, a quinolone chimera, displays an unprecedented broad spectrum of activity against photosynthetic prokaryotic and eukaryotic organisms, and nonphotosynthetic prokaryotic organisms. In contrast, eukaryotic non-photosynthetic cells are not affected by this hybrid compound.

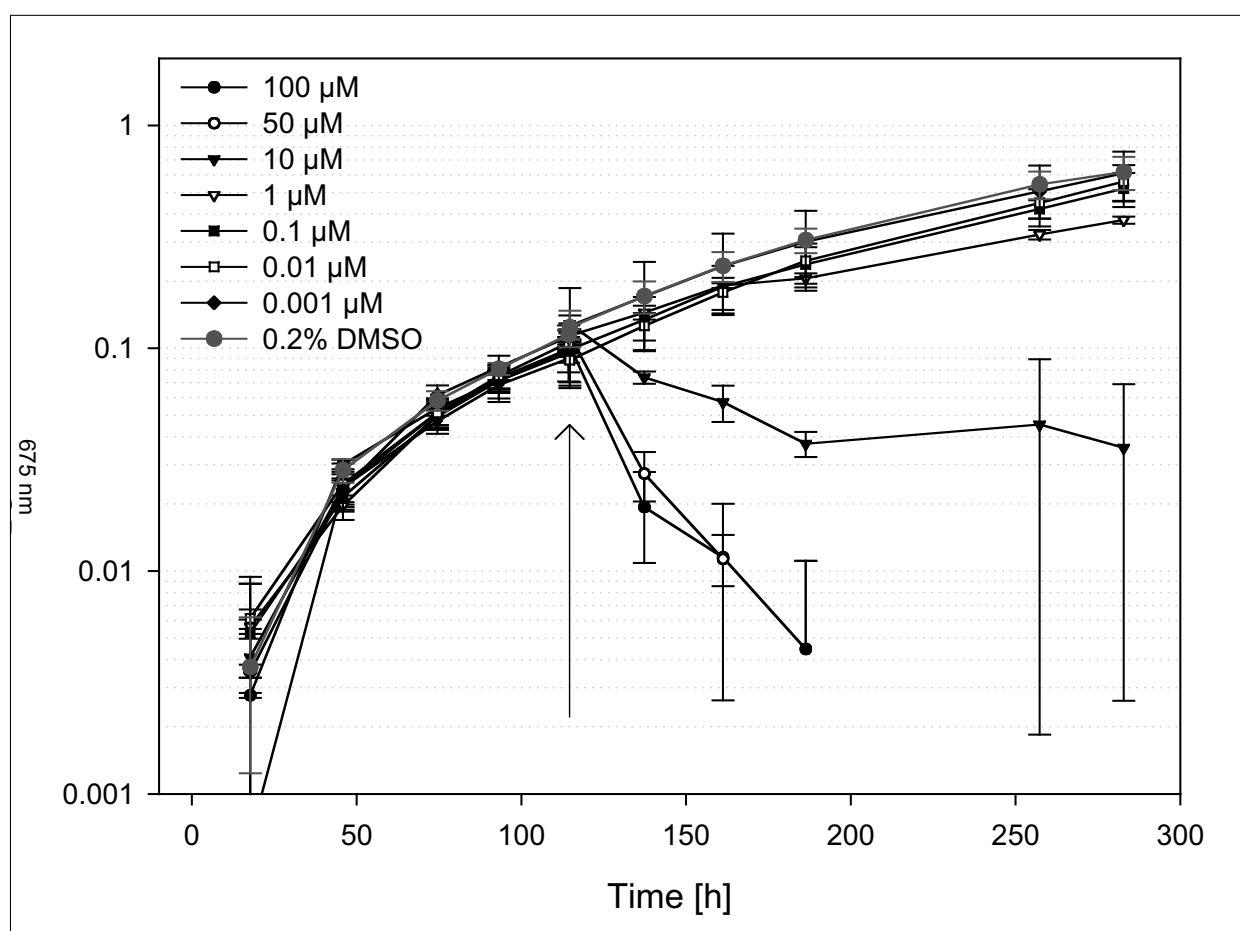

Fig. 5. Effect of nostocarboline iodide on Microcystis aeruginosa PCC 7806. Growth curves were measured by UV adsorption at $675 \mathrm{~nm}$, the arrow denotes the time of addition of nostocarboline. ${ }^{[45]}$ 
From these chemical and biological studies, it becomes evident that nostocarboline is an ideal candidate to suppress the initial stages of aquatic biofouling. Its advantages include

i) potent and fast reduction of phytoplankton growth,

ii) cheap and simple preparation,

iii) biogenic nature offering benefits in its potential registration ('natural algicide'),

iv) selective to photosynthetic organisms and

v) the structure is amenable to easy modification resulting in more potent derivatives.

These features become even more appealing in the context of increased banning of toxic tributyltin paints (TBT) all over the world. We think that cyanobacteria, and in particular nostocarboline, provide the longsought alternatives for antifouling metabolites and environmentally friendly replacements for TBT.

\section{Passive Inhibition of Biofouling}

Passive inhibition of biofouling is one of the current hot topics in biomaterials design. ${ }^{[49]}$ An appealing strategy consists of surface functionalization using proteinand cell-resistant polymers. Over the last decade, several protein-resistant polymers have been developed building on different architectures such as, for example, polyethyleneglycol (PEG), ${ }^{[50-52]}$ polyglycerols ${ }^{[53]}$ and peptoids. ${ }^{[54]}$ For long-term applications, however, their attachment on surfaces becomes crucial, as detachment of the polymers directly impairs their function. Various strategies for surface attachment of these protein-resistant matrices have developed, involving specific (thiols on gold), ${ }^{[50]}$ or non-specific (silanes ${ }^{[55]}$ or polyelectrolyte[56]) interactions. The problems associated with some of these anchors reside in the high reactivity against chemical functional groups such as nucleophiles (silanes) or electrophiles (thiols). For example, both thiols and silanes would react with the medium complex small molecule 3, and destroy its biological activity. For sophisticated strategies, anchor groups are needed that are unreactive ('orthogonal') to the functional groups present in small molecules. A promising group is derived from dihydroxyphenylalanine, a key component of mussel adhesive proteins. ${ }^{[57-60]}$

We have performed extensive synthetic, ${ }^{[61,62]}$ biogenetic, ${ }^{[63]}$ and mechanistic ${ }^{[64,65]}$ studies on the complex siderophore anachelin. ${ }^{[66,67]}$ In particular, we were fascinated by the ability of this natural iron chelator to efficiently bind iron ions. In order to sequester these ions, the chelators might need to recognize and bind to iron oxide

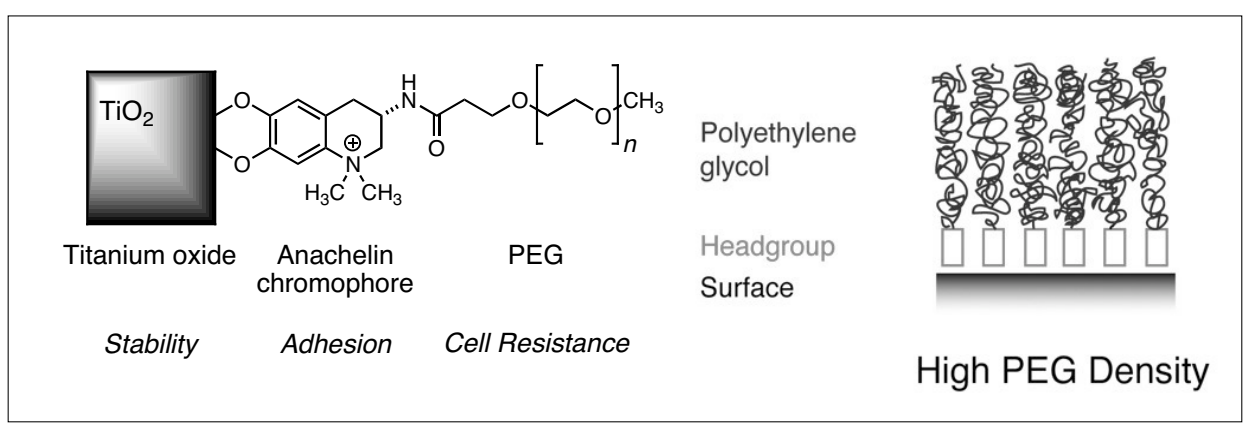

Fig. 6. The anachelin chromophore-PEG conjugate (left) efficiently binds to $\mathrm{TiO}_{2}$ surfaces forming thick adlayers (right)

surfaces. ${ }^{68,69]}$ We thus investigated the binding properties of anachelin, and in particular the affinity of the anachelin chromophore to metal oxide surfaces.[70] Interestingly, the anachelin chromophore binds to titanium oxide very efficiently (Fig. 6). By using this anchor, we could successfully immobilize PEG onto metal oxide surfaces as evidenced by various methods such as ellipsometry, $\mathrm{X}$-ray photoelectron spectroscopy and optical waveguide lightmode spectroscopy. When compared to control polymers containing anchor groups such as dopamine, DOPA $^{[57,58]}$ or mimosine, higher protein resistance combined with higher oxidative stability was observed for the anachelin chromophore modified surfaces. [70] The resulting modified surfaces can also be considered as natural product hybrids, as an inorganic support is linked through a natural product to a polymer such as PEG. This passive strategy against biofouling based on the anachelin chromophore thus presents a mild and orthogonal alternative to previous approaches and should find wide applications in areas ranging from biomaterials to biosensors.

\section{Conclusion}

In this highlight article, we have described how cyanobacterial natural products can be used and chemically modified to provide powerful strategies for the active and passive prevention of biofouling. Nostocarboline can serve as a powerful chemical modulator of algal growth and thus actively prevent biofouling. Advantages of nostocarboline, including potency, selectivity and its biogenic nature ('all natural'), might provide a useful alternative for toxic tributyltin antifouling paints. In the biomedical arena, the anachelin chromophore was shown to serve as a mild and orthogonal anchor for the immobilization of polymers to render surfaces protein-resistant. Its advantages include high selectivity, orthogonality and high protein-resistance for single site attachments. These examples demonstrate that the molecular secrets locked in natural products can be exploited by synthetic chemistry to find unique applications in other fields, and that biogenic metabolites provide molecular solutions to important problems in today's society.

\section{Acknowledgments}

I warmly thank my coworkers past and present, in particular Dr. Yann Bethuel, Damien Barbaras, Tobias Brütsch, Barbora Malisova and Sina Saxer, for their great experimental and intellectual efforts. In addition, such transdisciplinary research would not be possible without my excellent collaborators in limnology at the University of Zurich, Dr. Judith Blom and Prof. Dr. Friedrich Jüttner, and in materials science at ETH Zürich, Prof. Dr. Marcus Textor. I am also grateful to Dr. Stefan Zürcher and Dr. Samuele Tosatti of SurfaceSolutionS GmbH and Dr. Hans Locher and Dr. Christian Hubschwerlen of Actelion AG for successful collaborations. Financial support from Prof. Dr. Erick M. Carreira during my habilitation (2002-2006) is gratefully acknowledged, as is support from the Roche Research Foundation, Swiss National Science Foundation, ETH Zürich and the Latsis Foundation.

Received: March 23, 2007

[1] G. A. Cordell, Phytochemistry 2000, 55, 463.

[2] M. S. Butler, J. Nat. Prod. 2004, 67, 2141.

[3] G. M. Cragg, D. J. Newman, K. M. Snader, J. Nat. Prod. 1997, 60, 52.

[4] D. J. Newman, G. M. Cragg, K. M. Snader, J. Nat. Prod. 2003, 66, 1022.

[5] L. Hall-Stoodley, J. W. Costerton, P. Stoodley, Nature Rev. Microbiol. 2004, 2 , 95.

[6] J. W. Costerton, Z. Lewandowski, D. E. Caldwell, D. R. Korber, H. M. LappinScott, Ann. Rev. Microbiol. 1995, 49, 711.

[7] M. A. Champ, Sci. Tot. Environ. 2000, 258, 21.

[8] A. S. Clare, Biofouling 1996, 9, 211.

[9] N. Fusetani, Nat. Prod. Rep. 2004, 21, 94.

[10] S. Abarzua, S. Jakubowski, S. Eckert, P. Fuchs, Bot. Mar. 1999, 42, 459.

[11] P. Bhadury, P. C. Wright, Planta 2004, $219,561$.

[12] E. Armstrong, K. G. Boyd, J. G. Burgess, Biot. Ann. Rev. 2000, 6, 221. 
[13] E. M. Gross, Crit. Rev. Plant Sci. 2003, 22, 313.

[14] G. D. Smith, N. T. Doan, J. Appl. Phycol. 1999, 11, 337

[15] S. Dobretsov, H. U. Dahms, P. Y. Qian, Biofouling 2006, 22, 43.

[16] H. U. Dahms, X. Ying, C. Pfeiffer, Biofouling 2006, 22, 317.

[17] B. Jaki, J. Orjala, J. Heilmann, A. Linden, B. Vogler, O. Sticher, J. Nat. Prod. 2000, 63, 339.

[18] R. E. Schwartz, C. F. Hirsch, D. F. Sesin, J. E. Flor, M. Chartrain, R. E. Fromtling, G. H. Harris, M. J. Salvatore, J. M. Liesch, K. Yudin, J. Ind. Microbiol. 1990, 5, 113.

[19] R. E. Moore, C. Cheuk, X. Q. G. Yang, G. M. L. Patterson, R. Bonjouklian, T. A. Smitka, J. S. Mynderse, R. S. Foster, N. D. Jones, J. K. Swartzendruber, J. B. Deeter, J. Org. Chem. 1987, 52, 1036.

[20] N. T. Doan, R. W. Rickards, J. M. Rothschild, G. D. Smith, J. Appl. Phycol. 2000, 12, 409.

[21] F. K. Gleason, J. L. Paulson, Arch. Microbiol. 1984, 138, 273.

[22] J. J. Pignatello, J. Porwoll, R. E. Carlson, A. Xavier, F. K. Gleason, J. M. Wood, J. Org. Chem. 1983, 48, 4035.

[23] U. Papke, E. M. Gross, W. Francke, Tetrahedron Lett. 1997, 38, 379.

[24] L. Hagmann, F. Jüttner, Tetrahedron Lett. 1996, 37, 6539.

[25] E. M. Gross, C. P. Wolk, F. Jüttner, J. Phycol. 1991, 27, 686.

[26] K. Stratmann, R. E. Moore, R. Bonjouklian, J. B. Deeter, G. M. L. Patterson, S. Shaffer, C. D. Smith, T. A. Smitka, J. Am. Chem. Soc. 1994, 116, 9935.

[27] R. Bonjouklian, T. A. Smitka, L. E. Doolin, R. M. Molloy, M. Debono, S. A. Shaffer, R. E. Moore, J. B. Stewart, G. M. L. Patterson, Tetrahedron 1991, 47, 7739.

[28] J. A. Bush, B. H. Long, J. J. Catino, W. T. Bradner, J. Antibiot. 1987, 40, 668.

[29] D. E. Nettleton, T. W. Doyle, B. Krishnan, G. K. Matsumoto, J. Clardy, Tetrahedron Lett. 1985, 26, 4011.

[30] S. Oka, M. Kodama, H. Takeda, N. Tomizuka, H. Suzuki, Agric. Biol. Chem. 1986 50, 2723.

[31] T. Tamaoki, H. Nomoto, I. Takahashi, Y. Kato, M. Morimoto, F. Tomita, Biochem. Biophys. Res. Commun. 1986, 135, 397.

[32] A. Furusaki, N. Hashiba, T. Matsumoto, A. Hirano, Y. Iwai, S. Omura, Chem. Commun. 1978, 800 .

[33] H. A. Fine, L. Kim, C. Royce, D. Draper, I. Haggarty, H. Ellinzano, P. Albert, P Kinney, L. Musib, D. Thornton, J. Clin. Oncol. 2005, 23, 115S

[34] J. R. Graff, A. M. McNulty, K. R. Hanna, B. W. Konicek, R. L. Lynch, S. N. Bailey, C. Banks, A. Capen, R. Goode, J. E. Lewis, L. Sams, K. L. Huss, R. M. Campbell, P. W. Iversen, B. L. Neubauer, T. J. Brown, L. Musib, S. Geeganage, D. Thornton, Cancer Res. 2005, 65, 7462 .
[35] R. W. Rickards, J. M. Rothschild, A. C. Willis, N. M. de Chazal, J. Kirk, K. Kirk, K. J. Saliba, G. D. Smith, Tetrahedron 1999, 55, 13513.

[36] L. K. Larsen, R. E. Moore, G. M. L. Patterson, J. Nat. Prod. 1994, 57, 419.

[37] R. B. Volk, J. Appl. Phycol. 2005, 17, 339.

[38] R. B. Volk, J. Appl. Phycol. 2006, 18, 145.

[39] S. Kodani, A. Imoto, A. Mitsutani, M. Murakami, J. Appl. Phycol. 2002, 14, 109.

[40] R. B. Volk, F. H. Furkert, Microbiol. Res. 2006, 161,180

[41] R. B. Volk, S. Mundt, J. Appl. Phycol. 2007, 19, 55.

[42] P. G. Becher, J. Beuchat, K. Gademann, F. Juttner, J. Nat. Prod. 2005, 68, 1793.

[43] E. Flores, C. P. Wolk, Arch. Microbiol. 1986, 145, 215.

[44] K. Matsubara, M. A. Collins, A. Akane, J. Ikebuchi, E. J. Neafsey, M. Kagawa, H. Shiono, Brain Res. 1993, 610, 90.

[45] J. F. Blom, T. Brutsch, D. Barbaras, Y. Bethuel, H. H. Locher, C. Hubschwerlen, K. Gademann, Org. Lett. 2006, 8, 737.

[46] K. Gademann, Chimia 2006, 60, 841.

[47] L. F. Tietze, H. P. Bell, S. Chandrasekhar, Angew. Chem., Int. Ed. 2003, 42, 3996.

[48] G. Mehta, V. Singh, Chem. Soc. Rev. 2002, 31, 324.

[49] P. Kingshott, H. J. Griesser, Current Opinion in Solid State \& Materials Science 1999, 4, 403.

[50] K. L. Prime, G. M. Whitesides, Science 1991, 252, 1164.

[51] N. P. Desai, J. A. Hubbell, Biomaterials 1991, 12,144

[52] J. H. Lee, J. Kopecek, J. D. Andrade, J Biomed. Mat. Res. 1989, 23, 351.

[53] C. Siegers, M. Biesalski, R. Haag, Chem. Eur. J. 2004, 10, 2831.

[54] A. R. Statz, R. J. Meagher, A. E. Barron, P. B. Messersmith, J. Am. Chem. Soc. 2005 , 127, 7972 .

[55] Z. Yang, J. A. Galloway, H. Yu, Langmuir 1999, 15, 8405.

[56] S. Pasche, S. M. De Paul, J. Voros, N. D. Spencer, M. Textor, Langmuir 2003, 19, 9216.

[57] J. L. Dalsin, L. Lin, P. B. Messersmith, S. Tosatti, J. Voros, M. Textor, Langmuir 2005, 21, 640 .

[58] J. L. Dalsin, B.-H. Hu, B. P. Lee, P. B. Messersmith, J. Am. Chem. Soc. 2003 , 125,4253

[59] J. H. Waite, M. L. Tanzer, Science 1981, 212,1038

[60] J. H. Waite, Int. Comp. Biol. 2002, 42, 1172.

[61] K. Gademann, Y. Bethuel, Org. Lett. 2004, 6, 4707.

[62] K. Gademann, Y. Bethuel, Angew. Chem. Int. Ed. 2004, 43, 3327.

[63] K. Gademann, ChemBioChem 2005, 6, 913.

[64] Y. Bethuel, K. Gademann, J. Org. Chem. 2005, 70, 6258 .
[65] K. Gademann, H. Budzikiewicz, Chimia 2004, 58, 212

[66] H. Beiderbeck, K. Taraz, H. Budzikiewicz, A. E. Walsby, Z. Naturforsch. C. 2000, 55, 681 .

[67] Y. Itou, S. Okada, M. Murakami, Tetrahedron 2001, 57, 9093.

[68] J. Yang, P. J. Bremer, I. L. Lamont, A. J. McQuillan, Langmuir 2006, 22, 10109.

[69] M. J. McWhirter, P. J. Bremer, I. L. Lamont, A. J. McQuillan, Langmuir $\mathbf{2 0 0 3}$ 19, 3575 .

[70] S. Zürcher, D. Wäckerlin, Y. Bethuel, B. Malisova, M. Textor, S. Tosatti, K. Gademann, J. Am. Chem. Soc. 2006, 128 1064. 